\title{
H714Q mutation in Wilson disease is associated with late, neurological presentation
}

\author{
R H J Houwen, J Juyn, T U Hoogenraad, J K Ploos van Amstel, R Berger
}

Department of
Paediatric
Gastroenterology,
Wilhelmina Children's
Hospital,
Postbox 18009,
NL-3501 CA Utrecht,
The Netherlands
R H J Houwen
J Juyn

Department of Neurology, University Hospital Utrecht Postbox 85500, NL-3508 GA Utrecht, The Netherlands $T$ U Hoogenraad

Clinical Genetics Centre Utrecht, Postbox 18009, NL-3501 CA Utrecht, The Netherlands J K Ploos van Amstel

Department of Metabolic Diseases, Wilhelmina Children's Hospital, Postbox 18009, NL-3501 CA Utrecht, The Netherlands

R Berger

Correspondence to: Dr Houwen.

Received 21 November 1994 Revised version accepted for publication 1 February 1995

\begin{abstract}
Wilson disease is an autosomal recessive copper storage disease resulting from an inability of the liver to excrete copper. Patients can present at a young age, generally with symptoms of liver copper intoxication, or later on, generally with neurological symptoms. The gene for Wilson disease has recently been cloned. Five mutations have been described so far, but only one is found frequently, H714Q. We analysed 38 Dutch symptomatic Wilson disease patients for the $H 714 Q$ mutation and correlated this finding with age and symptoms at presentation.
\end{abstract}

Ten patients homozygous for the $\mathbf{H} 714 \mathrm{Q}$ mutation presented at a mean age of $20 \cdot 3$ (SD 6.1) years, with either neurological symptoms or a Kayser-Fleischer ring. Six patients with a $\mathrm{H} 714 \mathrm{Q}$ mutation in one chromosome and an unknown mutation in the other chromosome presented at a mean age of 17.8 (SD 5.8) years, with either neurological or hepatic symptoms. With the exception of one, all 22 patients with an uncharacterised mutation in both chromosomes presented with liver involvement, at a mean age of 9.9 (SD 2.4) years.

The difference in age at presentation between the H714Q/H714Q group and the patients with an unknown mutation was highly significant $(\mathrm{p}<0.0001)$. This suggests that the $H 714 Q$ mutation represents a relatively mild mutation, possibly with some residual function in the copper transporting protein, resulting in a slower build up of copper.

( $\mathcal{A}$ Med Genet 1995;32:480-482)

Wilson disease (WD) is an autosomal recessive disorder of copper metabolism with an incidence of approximately 1:50 $000 .^{1}$ It is the result of insufficient biliary copper excretion, and is characterised clinically by a gradual accumulation of copper, primarily in the liver and secondarily in the brain, kidneys, and other organs. Patients afflicted by this disease can present around the end of the first decade, generally with liver failure, or later on, generally with neurological symptoms. ${ }^{23}$

The gene responsible for Wilson disease has recently been cloned. ${ }^{4-7}$ It is now officially designated ATP7B, and encodes a copper transporting ATPase. At present five different mutations have been described. ${ }^{46}$ The most frequent mutation, $\mathrm{H} 714 \mathrm{Q}$, accounting for at least $30 \%$ of the mutations in the North American Wilson disease population, is a $\mathrm{C}_{2142}$ to A transversion, giving a glutamine instead of histidine residue at amino acid position 714 , within the phosphorylation domain of the ATP7B protein.

As genotype can have profound effects on the phenotype, the pivotal example being the relation between the $\Delta \mathrm{F} 508$ mutation and pancreatic insufficiency in cystic fibrosis, ${ }^{8}$ we investigated the relation between age at presentation and the H714Q mutation in Wilson disease patients.

\section{Materials and methods}

A total of 26 unrelated Dutch families with 38 symptomatic Wilson disease patients were investigated. The diagnosis in each patient was made by a lowered serum caeruloplasmin concentration in combination with either an increased 24 hour urinary copper excretion or a raised liver copper concentration. For each symptomatic patient the age and symptoms at presentation were recorded. The Student $t$ test was used to investigate differences in age at presentation between groups.

High molecular weight DNA was isolated from the peripheral blood leucocytes of patients by salt extraction. The probands were specifically tested for the H714Q mutation, which is the result of $\mathrm{a} \mathrm{C}_{2142}$ to $\mathrm{A}$ transversion in exon 14 of the WD gene. ${ }^{59}$ This transversion was analysed with PCR using as a forward primer

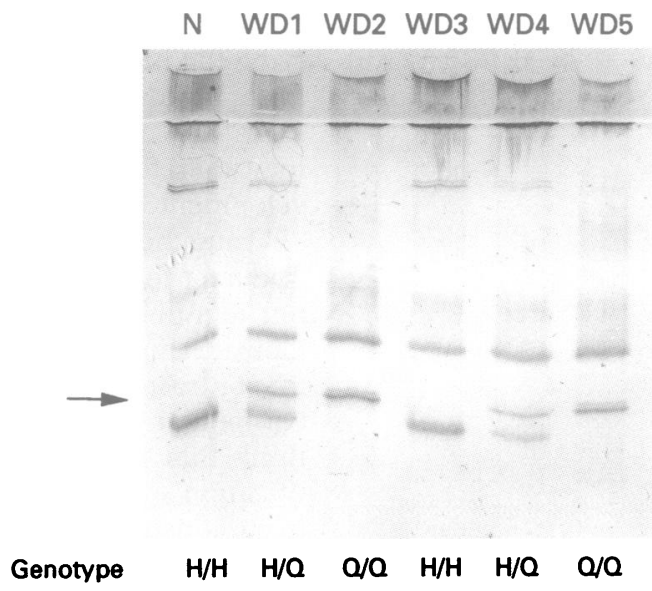

Figure 1 SSC analysis of exon 14 of the ATP7B gene. The gel shows a mobility shift representing the $H 714 Q$ amino acid substitution. Results for five Wilson disease patients (WD1 to WDS) and a normal control (N) are shown. Patients are either heterozygous for the $H 714 Q$ mutation ( $H / Q)$, homozygous for this mutation $(Q / Q)$, or without the amino acid substitution at position 714 or without the amino acid substitution at position
$(H / H)$. The arrow indicates the shifted band. 
H714Q and age at presentation

\begin{tabular}{|c|c|c|c|c|}
\hline Mutation & No & Age & & \\
\hline H714Q/H714Q & 10 & $20 \cdot 3(\operatorname{SD~} 6 \cdot 1)=$ & & \\
\hline $\mathrm{H} 714 \mathrm{Q} / ?$ & 6 & $17 \cdot 8(\operatorname{SD~} 5 \cdot 8)=$ & $p<0.0001$ & $\mathrm{p}<0.0001$ \\
\hline ?? & 22 & $9 \cdot 9(\mathrm{SD} 2 \cdot 4)=$ & & \\
\hline
\end{tabular}

3348 (CAG CTA CCA GAG AAG GAC ATG $\mathrm{G}$ ) and as a reverse primer 3349 (AGT TCT GCC TCA GGA GTG TGA C). ${ }^{5}$ Amplification was performed in 33 cycles, each cycle consisting of one minute denaturation at $94^{\circ} \mathrm{C}$, one minute annealing at $55^{\circ} \mathrm{C}$, and two minutes extension at $72^{\circ} \mathrm{C}$. The reaction mixture, a total of $100 \mu \mathrm{l}$, contained $400 \mathrm{ng}$ of high molecular weight DNA, $400 \mathrm{ng}$ of each primer, $150 \mathrm{mmol} / \mathrm{l}$ of each dNTP, $100 \mu \mathrm{g} / \mathrm{ml}$ bovine serum albumin (BSA), $67 \mathrm{mmol} / 1$ Tris- $\mathrm{HCl}$ (pH 8.8), $6.7 \mathrm{mmol} / 1 \mathrm{MgCl}_{2}, 10 \mathrm{mmol} / 1 \beta$-mercaptoethanol, $6.7 \mu \mathrm{mol} / 1$ EDTA, $16.6 \mathrm{mmol} / 1$ $\left(\mathrm{NH}_{4}\right)_{2} \mathrm{SO}_{4}, 10 \%$ dimethyl-sulphoxide (DMSO), and $40 \mathrm{U} / \mathrm{ml}$ of Taq DNA polymerase (PerkinElmer). The PCR results in a 337 bp fragment. ${ }^{5}$ The fragments were analysed for single strand conformation polymorphisms (SSCP) by automated electrophoresis on $12.5 \%$ homogenous PhastGels (Pharmacia-LKB) with native bufferstrips for $200 \mathrm{Vh}$ at $4^{\circ} \mathrm{C}$ according to the manufacturer's instructions. The DNA was visualised by silver staining. For some patients the amplified DNA was purified by ultra low gelling temperature electrophoresis, excised, and directly sequenced by the dideoxy chain termination reaction with a pUC sequencing kit (Boehringer Mannheim, Mannheim, Germany), using $\alpha-S_{35}$-dATP $(600 \mathrm{Ci} / \mathrm{mmol})$.

\section{Results}

A total of 38 symptomatic Wilson disease patients in 26 unrelated Dutch families were genetically tested for the $\mathrm{H} 714 \mathrm{Q}$ mutation in the ATP7B gene. Exon 14 was amplified by PCR and screened by SSCP (fig 1). The patients showed either the normal pattern $(n=$

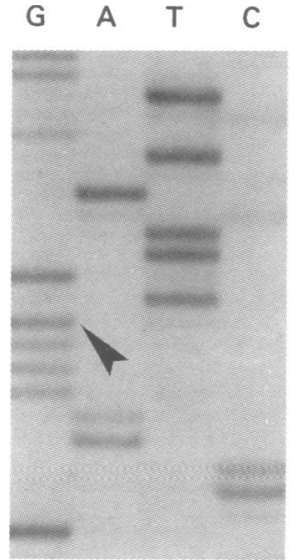

$\mathrm{N} ; \mathrm{N}$

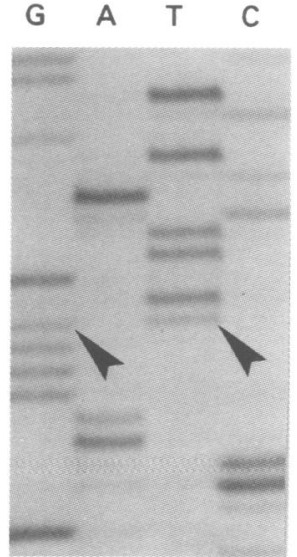

H7140; N
22), homozygosity for a band shift $(n=10)$, or heterozygosity for the two patterns ( $n=$ 6) (table). Direct sequence analysis of several patients showed that the shifted band is caused by the $\mathrm{C}_{2142}$ to $\mathrm{A}$ transversion (fig 2). No other abnormalities were identified in the amplified fragment. A panel of 40 normal people was similarly screened. All subjects showed the normal pattern.

The 10 patients homozygous for the $\mathrm{H} 714 \mathrm{Q}$ mutation presented at a mean age of $20 \cdot 3$ (SD 6.1) years (range 16-37 years) (table). However, patients with an at present unknown mutation in both chromosomes presented at a mean age of 9.9 (SD 2.4) years (range 6-15 years $)(p<0 \cdot 0001)$. Patients with a $\mathrm{H} 714 \mathrm{Q}$ mutation in one chromosome and a so far unknown mutation in the other, turned out to have an intermediate age at presentation: $17 \cdot 8$ (SD 5.8) years (range 10-24 years), significantly different $(p<0 \cdot 0001)$ from patients with an unknown mutation in both chromosomes but not from patients homozygous for the $\mathrm{H} 714 \mathrm{Q}$ mutation.

Nine out of the 10 patients homozygous for the $\mathrm{H} 714 \mathrm{Q}$ mutation presented with neurological or psychiatric symptoms, although in some patients concomitant liver cirrhosis was found at diagnosis. In one patient homozygous for the H714Q mutation a Kayser-Fleischer ring was accidently discovered when he went to the ophthalmologist for a new pair of glasses. The probable diagnosis of Wilson disease in this patient was subsequently proven by standard biochemical methods. This extrahepatic mode of presentation was very different from the 22 patients with an at present uncharacterised mutation in both chromosomes. Twenty of these patients presented with severe liver disease and half of those progressed to overt liver failure. One patient presented with abdominal pain. During subsequent investigations raised transaminases were discovered, which led to the diagnosis of Wilson disease in this patient. One other patient presented with neurological symptoms. At 15 years of age this patient was the oldest in this group. Three out of six
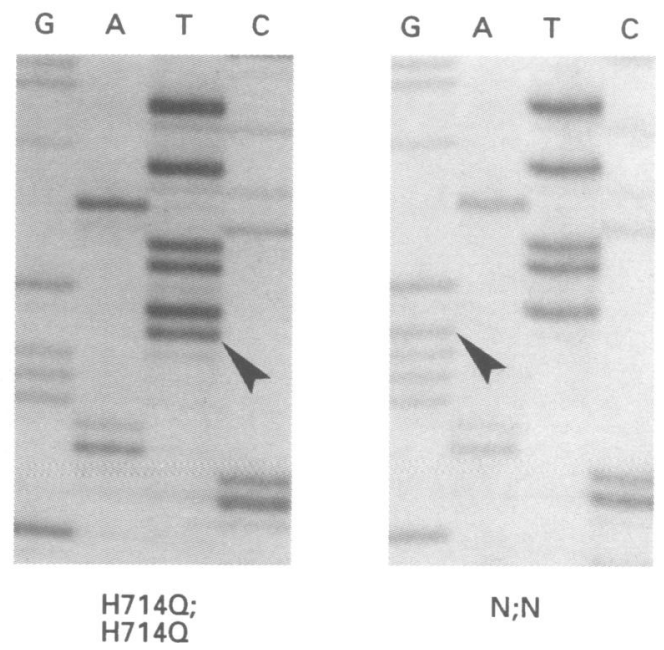

$N ; N$

Figure 2 DNA sequence gels showing the H714Q mutation in exon 14 of the ATP7B gene. The arrows indicate the nucleotide at position 2142 in the non-coding DNA strand, normally a guanine (cytosine in the coding strand). The left gel shows a normal control. The other three gels show Wilson disease patients that are, from left to right, heterozygous for $H 714 Q$, homozygous for $H 714 Q$, and homozygous for the normal sequence. 
patients with the H714Q mutation in one chromosome and an unknown mutation in the other presented with neurological symptoms, one with ascites owing to end stage liver disease and two with jaundice.

\section{Discussion}

Wilson disease can manifest either with hepatic symptoms, generally around the age of 10 , or later on, generally with neurological symptoms. ${ }^{23}$ While presentation in the second decade of life seemed to be more prevalent in specific populations, the hypothesis of genetic heterogeneity, possibly owing to different mutations, has been put forward. ${ }^{10}$ Subsequently indirect evidence was obtained that a specific mutation might be responsible for late, neurological presentation because of its association with a specific D13S31 allele in the Dutch Wilson disease population. ${ }^{11}$

We now find that the $\mathrm{H} 714 \mathrm{Q}$ mutation is indeed associated with late, neurological presentation in Wilson disease. Given the very significant difference in age at presentation between patients with and without an H714Q mutation, we hypothesise that this mutation probably leaves the ATP7B protein with some residual copper excretory capacity. Although the histidine residue in the phosphorylation domain of ion transport ATPases is strongly conserved between species, ${ }^{6}$ and consequently should be important for the function of the protein, this mutation does not result in a premature stop codon or frameshift, so preservation of some excretory function does not seem unlikely. However, some rare mutations have been described that result in a premature stop codon or a frameshift. ${ }^{46}$ Although no correlation with phenotype has been given yet, patients with this type of mutation might pres- ent at a young age with liver involvement, owing to a totally non-functional ATP7B protein.

It is unclear why the $\mathrm{H} 714 \mathrm{Q}$ mutation has become that prevalent in the United States, the Russian, ${ }^{5}$ as well as the Dutch Wilson disease population. The existence of a carrier advantage, protecting against a state of copper deficiency seems unlikely, because this is a very rare event in people not on parenteral nutrition. ${ }^{1}$ Probably chance effects are responsible for the high prevalence of the $\mathrm{H} 714 \mathrm{Q}$ mutation within the Wilson disease population.

We would like to express our gratitude to the families and their physicians for their cooperation. This study was supported by physicians for their cooperation. This study was
the Netherlands Digestive Disease Foundation.

1 Danks DM. Disorders of copper transport; In: Stanbury JB, Wyngaarden JB, Fredrickson DS, eds. The metabolic basis of
inherited disease. New York: McGraw-Hill, 1989:1411-21. 2 Houwen RHJ, Van Hattum J, Hoogenraad TU. Wilson disease. Neth f Med 1993;43:26-37.

3 Brewer GJ, Yusbasiyan-Gurkan V. Wilson disease. Medicine (Baltimore) 1992;71:139-64.

(Baltimore) 1992;71:139-64.
4 Bull PC, Thomas GR, Rommens JM, Forbes JR, Cox DW. Bull PC, Thomas GR, Rommens JM, Forbes JR, Cox DW.
The Wilson disease gene is a putative copper transporting P-type ATPase similar to the Menkes gene. Nature Genet 1993;5:327-37.

5 Petrukhin K, Fischer SG, Pirastu M, et al. Mapping, cloning and genetic characterization of the region containing the Wilson disease gene. Nature Genet 1993;5:338-43.

6 Tanzi RE, Petrukhin K, Chernov I, et al. The Wilson disease gene is a copper transporting ATPase with homology to the Menkes disease gene. Nature Genet 1993;5:344-50.

7 Yamaguchi Y, Heiny ME, Gitlin JD. Isolation and characterization of a human liver cDNA as a candidate gene for Wilson disease. Biochem Biophys Res Commun 1993, 197:271-7.

8 Hamosh A, Corey $M$ and the Cystic Fibrosis GenotypePhenotype Consortium. Correlation between genotype and phenotype in patie

9 Petrukhin K, Lutsenko S, Chernov I, Ross BM, Kaplan JH, Gilliam TC. Characterization of the Wilson disease gene encoding a P-type copper transporting ATPase: genomic encoding a P-type copper transporting ATPase: genomic
organization, alternative splicing, and structure/function organization, alternative splicing, and structure

predictions. Hum Molec Genet 1994;3:1647-56.
10 Cox DW, Fraser FC, Sass-Kortsak A. A genetic study of Wilson's disease: evidence for heterogeneity. Am $\mathcal{F}$ Hum Genet 1972;24:646-66.

11 Houwen RHJ, Berger R, Cox DW, Buys CHCM. Allelic association for Wilson disease-D13S31. f Hepatol 1992, 16:S15. 